04

\title{
Повышение эффективности полимерного нанокомпозита для формирования фотонных структур методом оптической записи
}

\author{
( Ю.Э. Бурункова, Д. Альхалил, Д.С. Свяжина匹 \\ Университет ИТМО, \\ 197101 Санкт-Петербург, Россия \\ ฯ e-mail: d.sviazhina@gmail.com \\ Поступила в редакцию 22.05.2020 г. \\ В окончательной редакции 03.06.2020 г. \\ Принята к публикации 03.06.2020 г.
}

\begin{abstract}
Представлено исследование условий оптимизации оптического регистрирующего материала для эффективной записи брэгговских решеток методом многолучевой интерференции на основе фоточувствительных акрилат-уретановых нанокомпозитов с наночастицами оксида кремния. Показано, что выбор наиболее эффективных мономеров и их концентраций в нанокомпозите в зависимости от их строения и скорости полимеризации с последующим определением оптимальной для данного состава интенсивности записывающего излучения позволяет регулировать условия для диффузии компонент, оптимизируя возможности для их перераспределения и формирования областей с различными показателями преломления в регистрирующей среде. Результаты исследования будут полезны для создания данным методом сложных 2D и 3D фотонных структур на основе целенаправленной модификации светочувствительных полимерных нанокомпозитов, обладающих разными свойствами (люминесцентными, нелинейно-оптическим и др.).
\end{abstract}

Ключевые слова: полимерный композит, наночастицы, фотонная структура, оптическая запись, брэгговские решетки, уретан-акрилатные мономеры.

DOI: $10.21883 /$ OS.2020.10.50023.167-20

\section{Введение}

Полимерные нанокомпозиты используются для создания голографическим методом объемных фотонных структур в полимерной матрице [1]. При воздействии неоднородного светового поля, представляющего собой результат интерференции нескольких световых пучков, в светочувствительной смеси инициируется процесс полимеризации, который стимулирует начало диффузии мономеров и наночастиц. Полимеризация и диффузия определяют механизм записи голограммы, которая формируется в результате создания периодического распределения областей с разными показателя преломления [2]. Как правило, жидкие светочувствительные фотополимеризующиеся материалы для голографии содержат в своем составе смесь мономеров и различные неорганические наночастицы. Известно значительное число работ, посвященных записи фотонных структур на фотополимерных нанокомпозитах, в которых исследуются параметры и условия записи, варьируются неорганические наночастицы, предлагаются модели протекающих процессов $[3,4]$. Однако до сих пор остается недостаточно изученным вопрос о критериях выбора и механизме влияния мономеров для получения фотонных структур с оптимальными свойствами.

В данной работе представлены результаты выбора мономеров для получения оптимального состава нанокомпозита, а также параметров оптической записи для повышения эффективности формирования фотонных структур - решеток Брэгга.

\section{Использованные материалы}

Светочувствительные составы, использованные в данных исследованиях, состояли из смеси коммерчески доступных мономеров, наночастиц оксида кремния и инициатора фотополимеризации. Мономеры: смесь изомеров диуретандиметакрилата (UDMA, показатель преломления $n=1.485,436909$ Aldrich); изодецилакрилат (IDA, показатель преломления $n=1.442$, 408956 Aldrich), карбоксиэтилакрилат (2-Carboxyethyl acrylate, 2Car, показатель преломления $n=1.457$, Aldrich, № 552348). Наночастицы: оксид кремния $\mathrm{SiO}_{2}$ диаметром $7 \mathrm{~nm}$ (Aldrich № 066K0110). Инициатор: Bis(.eta.5-2,4-cylcopentadien-1-yl)-bis(2,6-difluoro3-(1H-pyrrol-1-yl)-phenyl) titanium (Irgacure 784, Irg784).

\section{Приготовление нанокомпозита}

Технология получения нанокомпозитов заключается в следующем: смесь мономеров в течение 2 h интенсивно перемешивает на электромагнитной мешалке. Далее в смесь порционно вводят наночастицы $\mathrm{SiO}_{2}\left(10 \% \%_{\text {weight }}\right)$, добавляют толуол для уменьшения вязкости смеси и перемешивают $24 \mathrm{~h}$. Далее добавляют инициатор фотополимеризации $\operatorname{Irg} 784(0.5 \%$ weight $)$. Толуол выпаривают при температуре $35^{\circ} \mathrm{C}$ до постоянного веса смеси. Полученную композицию сохраняют при температуре $25^{\circ} \mathrm{C}$. Мономерный состав нанокомпозитов представлен в таблице. 
Мономерные составы нанокомпозитов

\begin{tabular}{c|c|c}
\hline № нанокомпозита & Мономеры & $\begin{array}{c}\text { Концентрации } \\
\text { мономеров, \% }\end{array}$ weight \\
\hline 1 & UDMA & 100 \\
2 & UDMA/IDA & $80 / 20$ \\
3 & UDMA/IDA & $75 / 25$ \\
4 & UDMA/IDA/2Car & $75 / 15 / 10$
\end{tabular}

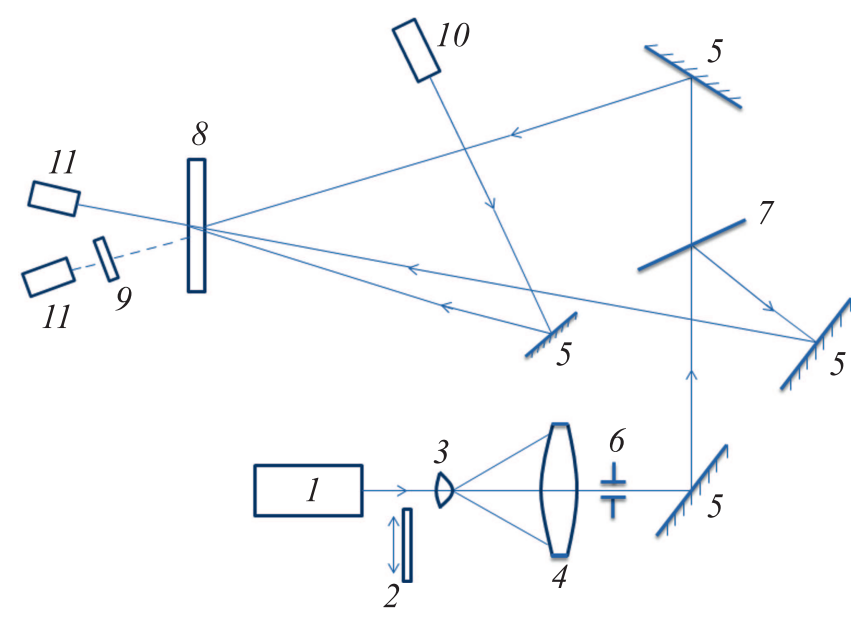

Рис. 1. Схема установки для записи голографических решеток. 1 - DPSS лазер $(\lambda=532 \mathrm{~nm}) ; 2,9$ - светофильтры; 3,4 - широкоапертурный телескоп; 5 - поворотные зеркала; 6 - апертурная диафрагма; 7 - светоделитель; 8 - образец с мономерной композицией; 10 - точечный лазерный модуль $(\lambda=635 \mathrm{~nm}) ; 11-$ фотоприемники.

\section{Методика голографической записи решеток}

Приготовленная по описанной выше методике мономерная композиция использовалась в дальнейшем для приготовления образцов. Капля состава помещается между стеклом и лавсановой пленкой и сдавливается прессом. Толщина формируемого слоя регулируется при помощи прокладок толщиной $55 \mu \mathrm{m}$. Для голографической записи решеток использовалась схема схождения пучков в попутном направлении, которая формировала пропускающие голограммы. Запись производилась по схеме, приведенной на рис. 1. Луч твердотельного одномодового DPSS лазера 1 с длиной волны $532 \mathrm{~nm}$ мощностью $100 \mathrm{~mW}$ расширялся с помощью линз 3 и 4, образующих настроенный на бесконечность широкоапертурный телескоп. Далее из этого пучка диафрагмой 6 диаметром $10 \mathrm{~mm}$ вырезалась световая зона с близким к гауссову распределением интенсивности. Для изменения направления пучка по схеме использовались поворотные зеркал 5. Светоделитель 7 разделял падающий на него световой пучок на два канала. Оба пучка фокусировались на образце для записи 8. Мощность излучения регулировалась светофильтром 2. Соотношение интенсивно- стей записывающих пучков было $1: 1$, которые имели вертикальную $(s)$ поляризацию. Пучки сводились под углом, обеспечивающим период решетки порядка $2 \mu \mathrm{m}$. Кинетика формирования решетки и дифракционной эффективности контролировалась в реальном времени при помощи излучения вспомогательного лазера $(10$, рис. 1$)$ с длиной волны $635 \mathrm{~nm}$, падающего на образец под углом Брэгга. Дифрагированный луч (на схеме показан пунктиром) падал на фотоприемник $(11$, рис. 1$)$, сигнал с которого записывался электронным самописцем и отображался на экране монитора компьютера. Второй фотоприемник регистрировал момент начала и конца процесса записи решетки.

Полное время экспонирования образца составляло обычно $5 \mathrm{~min}$ при плотности мощности $1-15 \mathrm{~mW} / \mathrm{cm}^{2}$. Дифракционная эффективность (ДЭ) записанной решетки рассчитывалась как отношение интенсивности дифрагированного луча 1-го порядка к интенсивности падающего луча.

\section{Результаты и обсуждение}

При исследовании нанокомпозитов для оптической записи фотонных структур методом многолучевой интерференции, как правило, основываются на следующих принципах. Механизм записи состоит в том, что при наложении интерференционной картины на мономерный слой в светлых областях активно начинается полимеризация, и соответственно расходуется мономерный компонент, поэтому для выравнивания химического потенциала (концентрации) начинается диффузия мономеров из более темных областей в светлые, при этом наночастицы диффундируют в противоположном направлении - из более светлых в более темные области. Таким образом, в результате взаимодиффузии мономерного компонента и наночастиц формируются области, обогащенные полимерной составляющей, и области, обогащенные содержанием наночастиц. Поскольку показатели преломления полимера и наночастиц различаются, то в результате записи (облучения) в объеме нанокомпозита формируется структура из периодически распределенных областей с разными показателями преломления. При этом характер получаемой модуляции показателей преломления в среде соответствует закону распределения интенсивности излучения в голографическом поле - наложенной картине интерферирующих световых пучков. Отсюда следует правило, что при создании нанокомпозита следует выбирать наночастицы и мономеры с большой разницей показателей преломления. Светоотверждаемые мономеры, как правило, имеют показатели преломления от 1.44 до 1.60, тогда как величины показателей преломления неорганических наночастиц имеют большее разнообразие, например 1.46 для наночастиц оксида кремния и 4.20 для оксида титана. Сложность создания полимерного нанокомпозита для оптической записи определяется тем, что регистриру- 
ющая среда (как оптический материал) должна иметь низкое светорассеяние и быть оптически однородна. Осуществление этих требований связано с необходимостью решить проблемы совместимости разных по своей природе компонентов нанокомпозита: наночастицы это неорганические вещества, имеющие плохое сродство и, соответственно, низкую растворимость при концентрациях от нескольких процентов и более в органической среде - в мономерах. Чтобы повысить совместимость неорганической и мономерной компонент, используют модификацию поверхности наночастиц, например создание оболочки из органических веществ. Это приводит к повышению совместимости наночастиц с органической мономерной средой, а также препятствует их агрегации. Однако при этом следует учитывать, что после модификации размеры наночастиц не должны превышать 25-40 nm, чтобы нанокомпозит оставался малорассеивающей средой, пригодной для оптической записи.

Как показывает практика записи фотонных структур данным методом, вводя наночастицы в концентрациях от нескольких процентов и до нескольких десятков процентов, можно получить дифракционную эффективность (ДЭ) записанных решеток от нескольких процентов до почти $100 \%$ [5]. Однако точной корреляции между необходимой концентрацией наночастиц и достигаемой величиной ДЭ на сегодняшний день не выявлено. Как следует из изложенного, выбор мономеров и наночастиц определяется не только их показателями преломления, но и возможностью их совмещения с целью получить нерассеивающий гомогенный нанокомпозит, пригодный к оптической записи и позволяющий формировать фотонные структуры с оптимальными свойствами.

В данной работе при создании нанокомпозитов в качестве основы состава нанокомпозита был выбран мономер UDMA с показателем преломления в полимерном состоянии 1.50 и наночастицы оксида кремния диаметром $7 \mathrm{~nm}$ и показателем преломления 1.46. Выбор этих компонентов нанокомпозита был обусловлен тем, что данная пара обеспечивает существенную разницу показателей преломления, а также их строением. Мономер UDMA обладает двумя двойными связями $\mathrm{C}=\mathrm{C}$, что позволяет формировать при полимеризации не линейную, а сетчатую структуру полимера, а наличие связей $\mathrm{N}-\mathrm{H}$ способствует хорошей совместимости с наночастицами оксида кремния. Важно отметить, что для формирования гомогенного раствора нанокомпозита можно использовать наночастицы оксида кремния даже без их предварительной модификации, что обусловлено возможностью образовывать донорно-акцепторные связи между ОН-группами на поверхности наночастиц и $\mathrm{N}-\mathrm{H}-$ группами UDMA [6]. Как показали исследования, можно вводить в мономер UDMA наночастицы оксида кремния до $10 \%$ weight и получать прозрачный малорассеивающий материал, пригодный для записи (нанокомпозит-1, таблица). Данный нанокомпозит-1 и другие из таблицы,

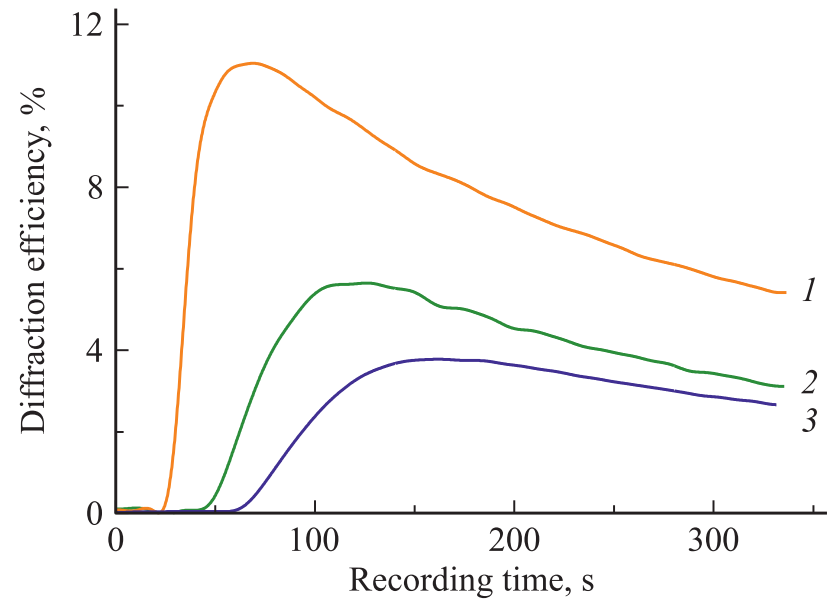

Рис. 2. Изменение ДЭ при записи решеток для нанокомпозитов разного мономерного состава: 1 - нанокомпозит-1; 2 - нанокомпозит- $2 ; 3$ - нанокомпозит-3.

полученные путем введения дополнительных мономеров, были использованы для записи решеток Брэгга. Результаты записи представлены на рис. 2 - это динамика изменения дифракционной эффективности (ДЭ) в течение процесса записи. Как видно по рис. 2, для всех составов наблюдается задержка - индукционный период - между началом экспонирования и началом формирования решетки.

Скорости изменения ДЭ в зависимости от состава нанокомпозита опосредованно характеризуют скорость формирования дифракционной решетки. На рис. 2 отчетливо видны различия в скорости изменения ДЭ в зависимости от мономерного состава нанокомпозитов. Так, максимальная скорость роста ДЭ наблюдается при использовании композиции с только UDMA мономером (нанокомпозит-1, кривая 1). Однако после окончания экспозиции с течением времени ДЭ решеток, записанных на таких составах, сильно падает. С большой вероятностью это можно объяснить тем, что мономер UDMA активно полимеризуется и, благодаря наличию двух двойных связей $\mathrm{C}=\mathrm{C}$, быстро образует сетчатую структуру. В результате облучения при записи наблюдается быстрый скачок ДЭ, обусловленный переходом из мономерного состояния $(n=1.485)$ в полимерное с большим показателем преломления $(n=1.505)$, но образовавшаяся сетчатая структура затрудняет взаимодиффузию и, соответственно, сегрегацию наночастиц и молекул мономера. Поскольку после окончания записи происходит диффузия оставшейся части незаполимеризовавшегося мономера, распределенного по всему объему и непродиффундировавшего во время экспонирования из-за образовавшейся сетки, то происходит выравнивание концентрации этих мономеров между темными и светлыми областями и наблюдается спад ДЭ.

Поскольку механизм формирования структур в нанокомпозите методом многолучевой интерференции опре- 
деляется процессами фотостимулированной полимеризации и вызванной ею диффузией компонентов, то необходимо соблюдение условия: при проведении записи время, в течение которого проходит диффузия наночастиц и мономеров для создания достаточно заметного изменения их концентрации в темных и светлых областях в объеме материала, должно быть меньше, чем время, за которое полимеризация материала пройдет настолько, что перераспределение наночастиц и мономеров будет невозможно. Выполнение этого условия дает хороший контраст записанной структуры внутри полимерной матрицы.

Использование при создании нанокомпозита смеси мономеров с разной скоростью полимеризации может быть способом, обеспечивающим проведение записи с оптимальной эффективностью. Введение мономера, который не полимеризуется в таких условиях или имеет меньшую, чем UDMA, скорость полимеризации, создает условия, замедляющие образование сетчатой структуры в объёме, и способствует таким образом возможности взаимодиффузии наночастиц и мономеров в течение более долгого времени. В качестве такого мономера был выбран IDA. Он практически не полимеризуется под действием облучения $380-532 \mathrm{~nm}$ с инициатором Irgacure 784. К тому же он не имеет функциональных групп, которые могли бы взаимодействовать с группами UDMA или наночастицами оксида кремния, затрудняя их диффузию. В данном случае мономер IDA является хорошим разбавителем для активно полимеризующихся молекул UDMA, что препятствует формированию полимерной сетки быстро по всему объему. Как видно на рис. 2, введение мономера IDA и увеличение его концентрации в нанокомпозите-1 снижает скорость роста ДЭ, и к тому же не наблюдается резкого скачка ДЭ (кривые 2 и 3 , нанокомпозит-2 и нанокомпозит-3 соответственно). Таким образом, можно утверждать, что модификация состава путем подбора мономеров с разной скоростью полимеризации позволяет влиять на условия диффузии мономеров и наночастиц при записи фотонных структур.

На рис. 2 видно также, что при данных условиях записи при добавке мономера IDA в нанокомпозит-1 (UDMA-SiO ${ }_{2}$ ) наблюдается уменьшение ДЭ. Как известно, одним из способов получения контрастных фотонных структур является выбор оптимальной интенсивности записывающего излучения. В данной работе было проведено варьирование плотности мощности при записи дифракционных решеток с периодом $2 \mu \mathrm{m}$ при использовании нанокомопозита-2 (UDMA/IDA- $\mathrm{SiO}_{2}$ ), результаты представлены на рис. 3.

Анализируя результаты записи, можно видеть, что при записи решеток непрерывным излучением с высокой плотностью мощности $\left(15-10 \mathrm{~mW} / \mathrm{cm}^{2}\right.$, рис. 3 , кривые 1 и 2) нанокомпозит так быстро полимеризуется, что взаимодиффузия компонентов практически не происходит. Результатом этого будет весьма малое изменение показателя преломления по всему объему полимерной

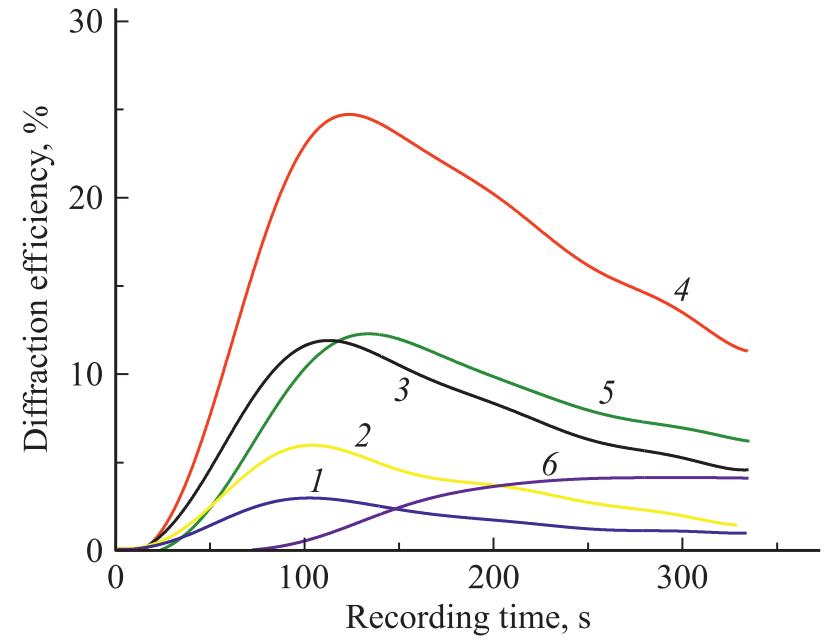

Рис. 3. Изменение ДЭ при записи решеток на нанокомпозите 2 при плотности мощности записывающего излучения $14.4(1), 10.5$ (2), $7.6(3), 5.5(4), 3.7(5), 1.3 \mathrm{~mW} / \mathrm{cm}^{2}$ (6).

матрицы и, как следствие, низкая конечная дифракционная эффективность записанной структуры (рис. 2, кривые 1 и 2).

При очень низких плотностях мощности до $1.3 \mathrm{~mW} / \mathrm{cm}^{2}$, (рис. 3, кривая 6) наблюдается очень длительный индукционный период, и полимеризация идет слишком медленно. Если увеличить время записи, то значения ДЭ будут плавно уменьшаться до минимальных (1-2\%) (кривая 6).

Наиболее высокие значения ДЭ (от 5.5 до 12\%) были получены при плотностях мощности записи от 3.7 до $7.6 \mathrm{~mW} / \mathrm{cm}^{2}$ (рис. 3, кривые 3-5). Таким образом, выбор определённой интенсивности записывающего излучения влияет на кинетику роста и конечную величину ДЭ формируемой решётки, а также на величину индукционного периода.

Используя формулу Когельника (1) и полученные значения ДЭ, были рассчитаны изменения значений показателя преломления $\Delta n$ для решеток, формируемых при различных интенсивностях записывающего излучения:

$$
\Delta n=\frac{\lambda_{1} \cos \theta_{\mathrm{B}} \arcsin \sqrt{\eta}}{\pi d},
$$

где $\theta_{\mathrm{B}}-$ угол Брэгга для записанной решетки, $d-$ толщина решетки, $\eta$-- дифракционная эффективность, $\lambda_{1}$ - длина волны восстанавливающего излучения

На рис. 4 представлены изменения значений показателя преломления $\Delta n$ в процессе записи решетки при интенсивности записи $5.5 \mathrm{~mW} / \mathrm{cm}^{2}$ для нанокомпозита-2.

Как видно по рис. 4, при записи сначала наблюдается рост показателя преломления, а затем после прохождения плавного максимума значения начинают уменьшаться, приближаясь к постоянной величине. Такое уменьшение после достижения максимальных значений показателя преломления, по-видимому, связано с тем, что к этому времени экспозиции вязкость среды возрастает и 
затрудняет взаимодиффузию компонент нанокомпозита, так что в основном идет полимеризация мономера. Недостатком нанокомпозита-2 является то, что наличие практически неполимеризующегося мономера IDA приводят к деградации значений ДЭ со временем.

С целью повышения величины и стабильности ДЭ решеток следует модифицировать нанокомпозит путем введения добавочного линейного мономера, скорость полимеризации которого ниже, чем у UDMA, но который, в отличие от имеющегося линейного мономеpa IDA, сможет полимеризоваться в данных условиях облучения. Такой подход позволит увеличить степень полимеризации после записи, что снизит деградацию ДЭ решеток с течением времени, а во время записи не будет увеличиваться количество образующихся сшивок. В качестве такого мономера был выбран 2Car, который при данных условиях облучения полимеризуется частично, образуя эластичные липкие слои. Мономер 2Car был добавлен в состав нанокомпозита-2 и был получен нанокомпозит-4, на котором при плотностях мощности излучения 5 и $7.2 \mathrm{~mW} / \mathrm{cm}^{2}$ были записаны решетки с ДЭ, равными соответственно 12\% и 15\%. Таким образом, предложенная модификация позволила при записи на нанокомпозите-4 создать дифракционную решетку со стабильной и вдвое более высокой максимальной дифракционной эффективностью.

Модификация состава позволила увеличить максимальное изменение показателя преломления на 0.004 , от 0.034 для нанокомпозита-2 до 0.038 для нанокомпозита-4, а также расширить диапазон плотностей мощности для записи от 1 до $7 \mathrm{~mW} / \mathrm{cm}^{2}$ (рис. 5). Для нанокомпозита-4 изменение показателя преломления практически не зависит от выбранной интенсивности записывающего пучка в данном диапазоне. В результате направленной модификации мономерного состава повысилась светочувствительность нанокомпозита. Понижение необходимой плотности мощности способствует достижению

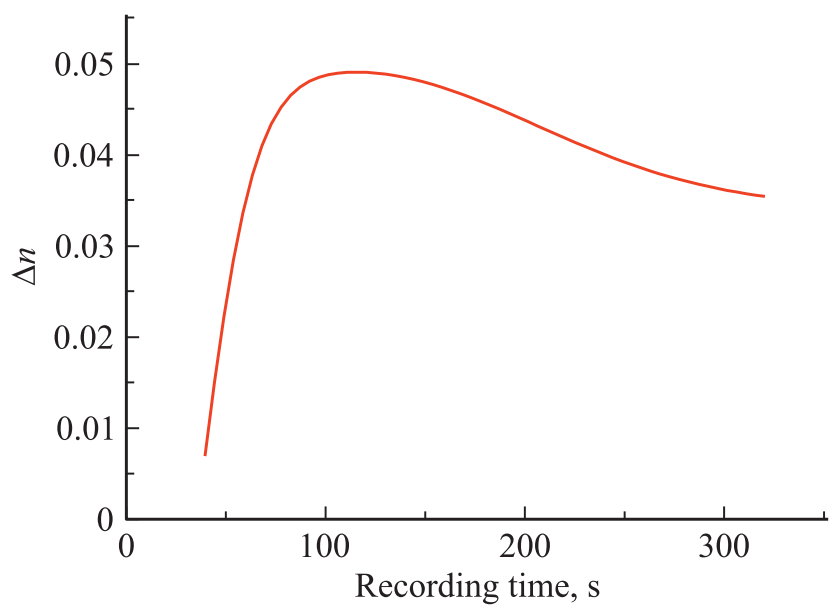

Рис. 4. Изменение показателя преломления во время записи решетки на нанокомпозите-2. Плотность мощности излучения при записи $5.5 \mathrm{~mW} / \mathrm{cm}^{2}$.

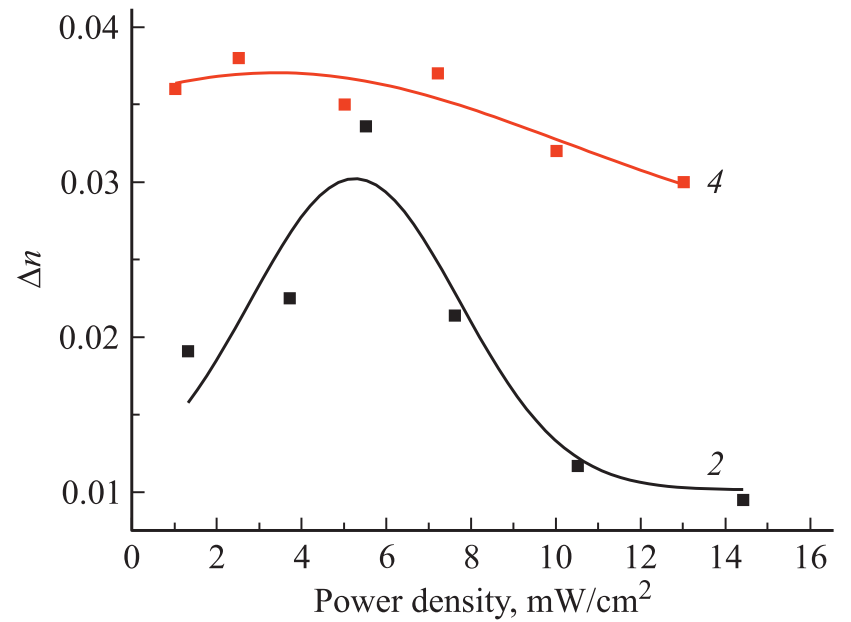

Рис. 5. Зависимости максимального изменения показателя преломления $\Delta n$ от плотности мощности при записи на нанокомпозите-4 (кривая 4) и нанокомпозите-2 (кривая 2).

оптимальных условий проведения процесса записи. Изза меньшей интенсивности облучения полимеризация всего объема достигается за больший период времени, соответственно, в материале медленнее растет вязкость, удлиняется время для осуществления массопереноса, что создает условия для более эффективного перераспределения наночастиц и мономеров в материале и в итоге приводит к увеличению значений ДЭ. К тому же реализуется возможность получить более высокую степень полимеризации мономеров, что позволяет сформировать более стабильные во времени решетки.

\section{Заключение}

В работе проведено исследование технологии создания эффективного оптического регистрирующего материала и условий его оптимизации для записи брэгговских решеток методом многолучевой интерференции. Это фоточувствительные полимерные нанокомпозиты с высоким содержанием наночастиц оксида кремния, которые исследованы с точки зрения выбора мономерных компонент для получения высоких значений ДЭ и стабильных записанных фотонных структур. Установлено, что определяющими факторами при выборе мономеров является их химическое строение и скорость полимеризации. Выбор наиболее эффективных мономеров и их концентраций в нанокомпозите в зависимости от их строения и скорости полимеризации с последующим определением оптимальной для данного состава интенсивности записывающего излучения позволяет регулировать условия для диффузии компонент, оптимизируя возможности для перераспределения компонентов и образования областей с различными показателями преломления в регистрирующей среде. При этом происходит также увеличение степени полимеризации всего объема 
нанокомпозита, что позволяет в целом повысить значения ДЭ и стабильность записанных фотонных структур. Поскольку светочувствительные материалы могут быть созданы на основе наночастиц, обладающих различными полезными свойствами (наночастицы с люминесцентными или нелинейно оптическими свойствами, с эффектом плазмонного резонанса и др.), то результаты проведенного исследования будут полезны для создания данным методом более сложных 2D и 3D фотонных структур на основе целенаправленной модификации многофункциональных нанокомпозитов.

\section{Конфликт интересов}

Авторы заявляют, что у них нет конфликта интересов.

\section{Список литературы}

[1] George D., Lutkenhaus J., Lowell D., Moazzezi M., Adewole M., Philipose U., Zhang H., Poole Z.L., Chen K.P., Lin Y. // Optics Express. 2014. V. 22. N 19. P 22421. doi 10.1364/OE.22.02242

[2] Tomita Y., Suzuki N., Chikama K. // Optics Lett. 2005. V. 30. N 8. P. 839. doi 10.1364/OL.30.000839

[3] Suzuki N., Tomita Y., Ohmori K., Hidaka M., Chikama K. // Optics Lett. 2006. V. 14. N 26. P. 12712. doi 10.1364/OE.14.012712

[4] Gleeson M. R., Sheridan J.T. // J. Opt. A: Pure Appl. Opt. 2009. V. 11. P. 1. doi 10.1088/1464-4258/11/2/024008

[5] Tomita Y., Hata E., Momose K., Takayama S., Liu X., Chikama K., Klepp J., Pruner C., Fally M. // J. Modern Optics. 2016. V. 63. S3, S1-S31. doi 10.1080/09500340.2016.1143534

[6] Burunkova J., Kokenyesi S., Csarnovics I., Bonyár A., Veres M., Csik A. // European Polymer J. 2015. V. 64. P. 189. doi 10.1016/j.eurpolymj.2015.01.011 